\title{
Additive Manufacturing of Poly[(R)-3-hydroxybutyrate-co-(R)-3-
}

\section{hydroxyhexanoate] Scaffolds for Engineered Bone Development}

\author{
Carlos Mota $^{1}$, Shen-Yu Wang ${ }^{2}$, Dario Puppi ${ }^{1}$, Matteo Gazzarri ${ }^{1}$, Chiara Migone ${ }^{1}$, \\ Federica Chiellini $^{1}$, Guo-Qiang Chen ${ }^{2}$ and Emo Chiellini ${ }^{1 *}$
}

${ }^{1}$ Laboratory of Bioactive Polymeric Materials for Biomedical and Environmental Applications (BIOLab), Department of Chemistry and Industrial Chemistry, University of Pisa, via Vecchia Livornese 1291, 56010 San Piero a Grado (Pi), Italy

${ }^{2}$ Department Biological Sciences and Biotechnology, School of Life Science, Tsinghua University, Beijing, 100084, China

\begin{abstract}
A wide range of poly(hydroxyalkanoate)s (PHAs), a class of biodegradable polyesters produced by various bacteria grown under unbalanced conditions, have been proposed for the fabrication of tissue engineering scaffolds. In this study, the manufacture of poly[(R)-3-hydroxybutyrate-co-(R)-3-hydroxyhexanoate] (or PHBHHx) scaffolds by means of an additive manufacturing technique based on a computer-controlled wetspinning system was investigated. By optimizing the processing parameters, threedimensional scaffolds with different internal architectures were fabricated based on a layer-by-layer approach. The resulting scaffolds were characterized by scanning electron microscopy, which showed a good control over the fibre alignment and a fully interconnected porous network, with porosity in the range of 79 to $88 \%$, fibre diameter from 47 to $76 \mu \mathrm{m}$ and pore size from 123 to $789 \mu \mathrm{m}$. Moreover, the resulting fibres presented an internal porosity connected to the external fibre surface as a consequence of the phase inversion process governing the solidification of the polymer solution. Scaffold compressive modulus as well as the yield stress and strain could be varied in a
\end{abstract}


certain range by changing architecture parameters. Cell culture experiments employing MC3T3-E1 murine pre-osteoblast cell line showed good cell proliferation after 21 days of culture. The PHBHHx scaffolds demonstrated promising results in terms of cell differentiation towards an osteoblast phenotype.

*Corresponding Author: emochie@dcci.unipi.it

Keywords: tissue engineering, scaffold, poly(hydroxyalkanoate)s, poly[(R)-3hydroxybutyrate-co-(R)-3-hydroxyhexanoate], wet-spinning, rapid prototyping, additive manufacturing

\section{Introduction}

Tissue Engineering (TE) is a domain that combines the principles of engineering and life sciences with the aim of providing substitutes that can temporarily replace defected tissues and support their regeneration (Langer and Vacanti, 1993). TE approach generally involves the employment of what is commonly referred to as scaffolds, eventually in combination with cells and bioactive agents, as temporary porous matrices mimicking the natural microenvironment to support and promote tissue regeneration. A wide range of polymeric materials, such as natural polysaccharides or synthetic polyesters, have been investigated in the past decades for the development of highly porous scaffolds suitable as an alternative to permanent implants (Puppi et al., 2010). Polyhydroxyalkanoates (PHAs) are a class of aliphatic polyesters, produced by many bacteria grown under unbalanced conditions (Steinbüchel and Valentin, 1995, Chen et al., 2001). Over the past years, different PHAs and their composites have been 
investigated for biomedical applications due to their biodegradability and biocompatibility (Chen et al., 2000, Chen and Wu, 2005). Differently to other polyesters of petrochemical origins that have been approved for biomedical applications, such as poly( $\varepsilon$-caprolactone) (PCL), PHAs comply with the concept of renewable development. The possibility of exploiting renewable resources, possibly agroindustrial waste (EU projects: Wheypol, Polyver, Animpol), for the production of polyesters for biomedical applications is nowadays considered a realistic strategy that can potentially replace their obtainment from petroleum derivatives (Morelli et al., 2013). Poly[(R)-3-hydroybutyrate] (PHB) is the most widely investigated PHA and has shown good compatibility with various cell lines, including osteoblasts, epithelial cell and ovine chondrocytes (Rivard et al., 1996, Nebe et al., 2001). Thanks to their piezoelectric properties, PHB and its copolymers with hydroxyvaleric acid, poly[(R)-3hydroxybutyrate-co-(R)-3-hydroxyvalerate] (PHBV) (Figure 1), have been particularly investigated for the engineering of bone tissue (Puppi et al., 2010).

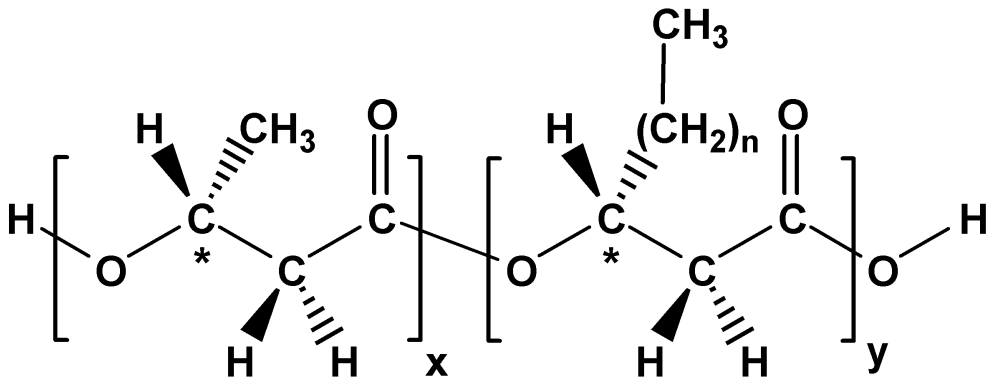

$\mathrm{n}=1$ Poly[(R)-3-hydroxybutyrate- co -(R)-3-hydroxyvalerate] (PHBV)

$\mathrm{n}=2$ Poly[(R)-3-hydroxybutyrate- co -(R)-3-hydroxyhexanoate] (PHBHHx)

Figure 1 - General basic structure of PHA copolymers.

Materials based on PHB were shown to produce a favourable bone tissue adaptation response in vivo with no evidence of an undesirable chronic inflammatory response, as well as no conclusive evidence of extensive structural breakdown after implantation 
periods up to 12 months (Doyle et al., 1991). PHBV foams implanted in rat femur defects have shown bone regenerative potential eliciting minimal inflammation and reduced fibrous tissue formation, throughout 6 weeks (Köse et al., 2004). In vivo studies showed that PHB and PHBV composite scaffolds reinforced with hydroxyapatite particles can integrate well with the host tissue to promote bone growth (Doyle et al., 1991, Chen and Wu, 2005, Jack et al., 2009). However, despite of the promising results achieved, PHB and PHBV brittleness can limit their application as in vivo load bearing tissue substitutes (Ye et al., 2009, Garcia-Garcia et al., 2012). As a member of the PHAs family, poly[(R)-3-hydroxybutyrate-co-(R)-3-hydroxyhexanoate) (PHBHHx) (Figure 1) is a promising biomaterial showing better ductility and processing properties in comparison with PHB and PHBV (Doi et al., 1995, Chen et al., 2001, Zhao K. et al., 2003). The main degradation products of PHBHHx, oligo [(R)-3-hydroxybutyrate-co(R)-3-hydroxyhexanoate], oligo [(R)-3-hydroxybutyrate $]$ and oligo [(R)-3hydroxyhexanoate], were demonstrated to be non-toxic to in vitro cell culture (Cheng et al., 2005, Sun et al., 2007, Zhao Y. et al., 2007). PHBHHx has a good piezoelectricity (Ke et al., 2012) and PHBHHx scaffolds have shown better cytocompatibility when cultured with osteoblasts and bone marrow cells in comparison with poly(lactic acid) (PLA) and PHB scaffolds (Wang Y. W. et al., 2004, Yang M. et al., 2004, Wang Y. W. et al., 2005b). Recent studies reported that microgrooved PHBHHx membranes (Wang Y et al., 2011), aligned electrospun PHBHHx fibres (Wang $\mathrm{Y}$ et al., 2012) and PHBHHx/PCL blends (Lim et al., 2013) supported the adhesion and proliferation of human mesenchymal stem cells . In addition, PHBHHx-based composites containing an osteoconductive or piezoelectric inorganic filler (e.g. bioactive glasses or $\mathrm{BaTiO}_{3}$ 
particles) have been investigated for bone regeneration approaches (Jing et al., 2008b, Garcia-Garcia et al., 2012, Ke et al., 2012, Wu et al., 2013).

Several techniques have been proposed for the fabrication of scaffolds with a porous structure that could support cell organization and activity in three dimensions, such as fibre bonding, electrospinning, freeze-drying, gas foaming and thermally-induced phase separation (Puppi et al., 2010, Clyne, 2011). In addition, rapid prototyping techniques based on additive fabrication principles, known as additive manufacturing (AM) or solid freeform fabrication techniques, which allows a precise control over the scaffold's internal architecture and external shape, have been recently proposed for TE scaffolds production (Salgado et al., 2004, Puppi et al., 2010, Clyne, 2011, Mota et al., 2012). Different processing techniques, such as salt-leaching (Wang Y. W. et al., 2004, Wang Y. W. et al., 2005a), freeze-drying (Jing et al., 2008a) and electrospinning (Wang Y et al., 2012), have been explored in the past years for the fabrication of PHBHHx scaffolds. However, to the best of our knowledge (Mota et al., 2012), rapid prototyping techniques have not been applied so far to PHBHHx.

Wet-spinning is a polymeric fibre fabrication process, based on non-solvent induced phase inversion, which involves the extrusion of a polymeric solution directly into a coagulation bath (Puppi et al., 2011a). The extruded filament of polymeric solution precipitates because of the solvent/non-solvent counter-diffusion that lowers polymer solubility, leading to the formation of a continuous polymer fibre. Solvent/non-solvent demixing causes the formation of a polymer-rich phase and polymer-lean phase that usually results in a sponge-like fibre morphology. In previous studies, non-woven meshes composed by wet-spun fibres made of different biodegradable polymers, such as PCL, PLA, chitosan and starch, were proposed for TE applications (Williamson and 
Coombes, 2004, Zhang et al., 2007, Tuzlakoglu et al., 2010, Puppi et al., 2011b, Puppi et al., 2011a). However, the techniques employed to assemble the wet-spun fibres into a 3D scaffold suffer from lack of structure reproducibility and production efficiency. To overcome these limitations, a computer-aided AM technique based on the controlled deposition of a wet-spun polymeric fibre was recently developed and successfully employed for the fabrication of 3D scaffolds made of PCL with a linear or a star molecular structure, achieving good control over internal architecture and external shape (Puppi et al., 2012, Mota et al., 2013).

The aim of the present study was the development of PHBHHx microstructures by means of a computer-aided wet-spinning technique that enables the fabrication layer by layer of polymeric scaffolds with predefined internal architecture and external shape. A commercial subtractive rapid prototyping system coupled with a syringe pump (Mota et $a l ., 2013)$ was employed to deposit with a predefined pattern a PHBHHx solution into a coagulation bath. The influence of different processing parameters, such as solution feed rate $(\mathrm{F})$, deposition velocity $\left(\mathrm{V}_{\mathrm{dep}}\right)$, inter-layer needle translation $\left(\mathrm{d}_{\mathrm{z}}\right)$ and lay-down pattern, on the scaffold morphology, in terms of porosity, pores geometry and pores size, were investigated by means of scanning electron microscopy (SEM) and differential scanning calorimetry (DSC). The developed scaffolds were further investigated for their compressive mechanical properties. Preliminary in vitro cytocompatibility was tested using MC3T3-E1 murine pre-osteoblast cells. 


\section{Materials and Methods}

\subsection{Materials}

Poly[(R)-3-hydroxybutyrate-co-(R)-3-hydroxyhexanoate] (PHBHHx, 12 mol\% HHx, $\mathrm{Mw}=300000 \mathrm{~g} / \mathrm{mol}$ ) was kindly supplied by Tsinghua University, Beijing (China). PHBHHx was purified before use according to the following procedure: i) the polymer was dissolved in 1,4 dioxane $(5 \% \mathrm{w} / \mathrm{v})$ under stirring at room temperature for $1 \mathrm{~h}$, ii) the solution was filtered under vacuum using filter paper, iii) the filtrate was slowly dropped into 10-fold volume water to precipitate $\mathrm{PHBHHx}$, iv) after precipitation the polymer was collected by filtering, v) the polymer was washed with distilled water and then ethanol, and vacuum dried and stored in a desiccator. All the solvents and chemical reagents were purchased from Sigma-Aldrich (Italy) and used as received.

\subsection{Scaffold fabrication}

PHBHHx was dissolved in chloroform $(25 \% \mathrm{w} / \mathrm{v})$ under stirring for $2 \mathrm{~h}$ at $30^{\circ} \mathrm{C}$ to obtain a homogeneous solution. Scaffold manufacturing was performed by means of a computer-controlled rapid prototyping machine (MDX-40A, ROLAND DG Mid Europe Srl, Italy) modified in-house to allow the production of 3D scaffolds composed of wetspun polymeric fibres (Mota et al., 2013). The prepared solution was placed into a glass syringe fitted with a stainless steel blunt needle with an inner diameter of $0.41 \mathrm{~mm}$ (gauge 21). A syringe pump (NE-1000, New Era Pump Systems Inc., Wantagh, NY, USA) was used to control the extrusion flow rate of the polymer solution into the coagulation bath (Figure 2a). A beaker containing ethanol was fixed to the fabrication platform and used as a coagulation bath. An initial distance between the needle tip and 
the bottom of the beaker $\left(\mathrm{Z}_{0}\right)$ of $2 \mathrm{~mm}$ was set in all the performed experiments. The 3D geometrical scaffold parameters (Figure 2b), including the distance between the fibre axis $\left(d_{2}\right)$, layer thickness $\left(d_{3}\right)$, scaffold external geometry and sizes, were designed using an algorithm developed in Matlab software (The Mathworks, Inc.). The combination of the $\mathrm{X}-\mathrm{Z}$ axis needle motion and of the $\mathrm{Y}$ axis platform motion allowed the fabrication of scaffolds layer-by-layer. The effect of different processing conditions, such as $\mathrm{F}, \mathrm{V}_{\mathrm{dep}}$, and $d_{z}$, for the fabrication of scaffolds with different $d_{2}(1000,500$ or $200 \mu \mathrm{m})$ and laydown pattern $\left(0-90^{\circ}\right.$ or $\left.0-45^{\circ}\right)$ were investigated. The resulting scaffolds were dried under vacuum and stored in a desiccator.

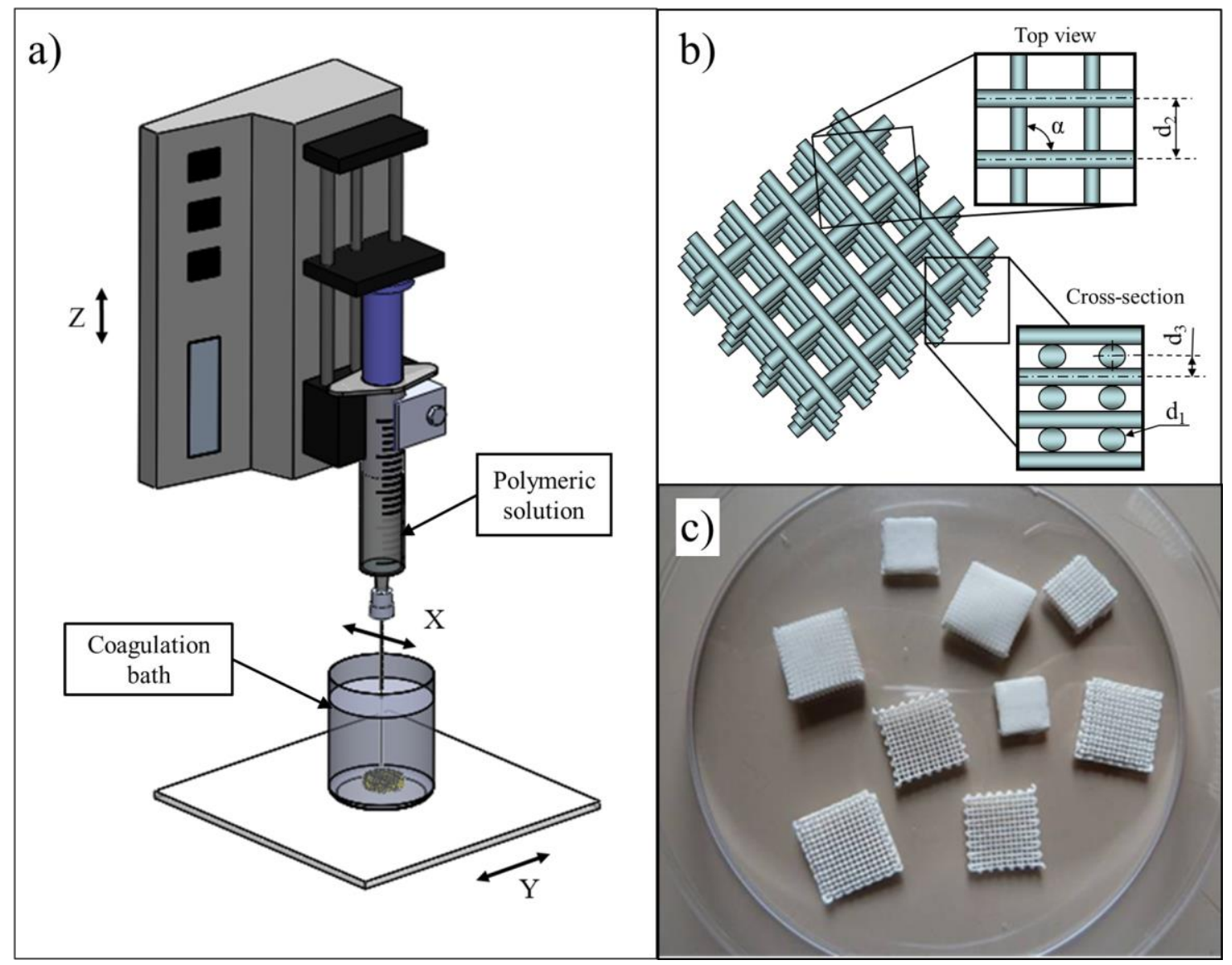

Figure 2 - a) Schematic representation of computer-aided wet-spinning apparatus, b) schematic representation of 3D scaffold $\left(0-90^{\circ}\right)$ showing architecture parameters and c) photograph of PHBHHx scaffolds with different external sizes and internal architecture. 


\subsection{Scanning electron microscopy analysis of PHA scaffolds}

Top view and cross-section morphology of the produced scaffolds was analyzed by scanning electron microscopy (SEM, model JEOL LSM 5600LV, Japan) under backscattered electron imaging at magnifications from $50 \mathrm{X}$ to $1000 \mathrm{X}$. The obtained SEM micrographs were processed with Image-Pro Plus software (Media Cybernetics, Silver Spring, USA) to calculate scaffold architecture parameters $\left(\mathrm{d}_{1}, \mathrm{~d}_{2}\right.$ and pore sizes) reported as average and standard deviations over 15 measurements per specimen.

\subsection{Differential scanning calorimetry analysis of PHA scaffolds}

The degree of crystallinity of the PHBHHx scaffolds was evaluated by means of differential scanning calorimetry (DSC, Mettler DSC-822, Mettler Toledo, Italy) under a nitrogen atmosphere of $80 \mathrm{ml} \cdot \mathrm{min}^{-1}$. The samples were heated from $-20^{\circ} \mathrm{C}$ to $180^{\circ} \mathrm{C}$ at a rate of $10^{\circ} \mathrm{C} / \mathrm{min}$. The melting enthalpy was determined by the endothermic peak recorded in the first scan. The percentage crystalline degree $\left(\% \mathrm{Cr}_{\mathrm{PHBHHx}}\right)$ was calculated as following (Yang Hua-Xiao et al., 2009):

$\% \mathrm{Cr}_{\mathrm{PHBHHx}}=\left(\triangle \mathrm{H}_{\mathrm{m}(\mathrm{PHBHH})} / \triangle \mathrm{H}^{0}{ }_{\mathrm{m}(\mathrm{PHB})}\right) \times 100 \%$

where $\Delta \mathrm{H}^{0}$ m(PHB) is the melting enthalpy of $100 \%$ crystalline PHB (146.6 J/g) and $\Delta \mathrm{H}_{\mathrm{m}(\mathrm{PHBHH})}$ is the melting enthalpy of PHBHHx measured by DSC.

\subsection{Porosity evaluation of PHA scaffolds}

The porosity of the scaffolds was estimated by referring to the method reported by Landers et al (Landers et al., 2002) and Shor et al (Shor et al., 2007) considering the 
architectural parameters obtained from SEM morphology analysis $\left(\mathrm{d}_{1}, \mathrm{~d}_{2}\right.$ and $\left.\mathrm{d}_{3}\right)$ and the orientation angle between fibres of two adjacent layers $(\alpha)$ (Figure $2 b$ ).

The total volume of the scaffold (V) can be calculated as:

$$
\text { Vscaffold }=d_{2}^{2} \quad d_{3}
$$

While the volume of a single fibre can be calculated as

$$
\text { Vfibre }=\frac{1}{2} \times \frac{x d_{1}^{2} d_{2}}{4}+\frac{1}{2} \times \frac{x d_{1}^{2}}{4} \times \frac{d_{2}}{\sin }=\frac{x d_{1}^{2} d_{2}}{8} \times 1+\frac{1}{\sin } \div
$$

The porosity $(\mathrm{P})$ of the scaffold is:

$$
P=1 \frac{\text { Vfibre }}{\text { Vscaffold }}
$$

From Eq. (2), (3), (4), the porosity of the scaffold can be calculated as Eq. (5):

$$
P=1 \frac{d_{1}^{2}}{8} \times 1+\frac{1}{d_{2} d_{3}} \times 1
$$

Since an accurate measurement of $d_{3}$ from cross-section SEM micrographs was often difficult, another method based on crystalline degree was applied to better estimate the porosity (Li X. T. et al., 2008):

$$
P=\frac{D p \quad D f}{D p}
$$

The overall density $\mathrm{D}_{\mathrm{f}}$ was evaluated considering the weight and volume of non-porous scaffolds, while the density of the porous scaffolds $D_{p}$ was given by:

$$
D p=\frac{1}{\frac{1}{D a}+\frac{X c}{D c}}
$$

Where $\mathrm{Xc}$ is the degree of crystallinity of the scaffold (determined by DSC as previously described), Da is the density of amorphous polymer, Dc is the density of 
$100 \%$ crystalline polymer. In the case of PHBHHx, the values of Da and Dc are 1.177 $\mathrm{g} / \mathrm{ml}$ and $1.260 \mathrm{~g} / \mathrm{ml}$, respectively (Li X. T. et al., 2008).

\subsection{Compressive mechanical characterization of PHA scaffolds}

Scaffold compressive mechanical properties were evaluated using an Instron 5564 Uniaxial Testing System (Canton, MA, USA) with a $2 \mathrm{kN}$ load cell. Five samples of each kind of scaffold with a square base area of $9.0 \times 9.0 \mathrm{~mm}$ and a thickness in the range 2-3 $\mathrm{mm}$ (50 layers), depending on the structural parameters, were characterized. The specimens were tested at a crosshead speed of $0.5 \mathrm{~mm} \cdot \mathrm{min}^{-1}$ between two parallel steel plates until a maximum strain of $95 \%$, and the stress-strain curves were analysed using Merlin IX software. The stress was defined as the measured force divided by the total area of the apparent cross-section of the scaffold, whilst the strain was evaluated as the ratio between the scaffold height variation and its initial height. Compressive modulus was calculated from the stress-strain curves as the slope of the initial linear region, avoiding the toe region by applying a pre-load to the specimens, while compressive yield strength and strain were calculated at the yield point.

\subsection{Biological evaluation of PHA scaffolds}

\subsubsection{Cell attachment and proliferation}

Scaffold samples were sterilized with ethanol (70\%) for three hours (Park Su A et al., 2011, Whited et al., 2011, Sarkar et al., 2013). When the ethanol solution was removed, scaffolds were washed repeatedly using Dulbecco's phosphate buffer saline (DPBS) containing penicillin/streptomycin solution (1\%). Scaffolds were left overnight in this solution that was then substituted with complete culture medium before cell seeding. 
Mouse calvaria-derived, preosteoblastic cells MC3T3-E1 subclone 4 were obtained from the American Type Culture Collection (ATCC CRL-2593) and cultured as a monolayer in Alpha-modified Minimum Essential Medium ( $\alpha$-MEM, Sigma), containing ribonucleosides, deoxyribonucleosides and sodium bicarbonate. The medium was supplemented with L-glutamine $(2 \mathrm{mM})$, penicillin/streptomycin solution (100 U/ml:100 $\mu \mathrm{g} / \mathrm{ml})(1 \%)$, fetal bovine serum (10\%) and antimycotic. Confluent MC3T3E1 cells at passage 27 were trypsinized ( $0.25 \%$ trypsin-EDTA solution), detached from the flask and seeded on the scaffold specimens, in a number of $0.5 \times 104$ and in total volume of $200 \mu \mathrm{l}$ of complete culture medium. After one hour of incubation at $37^{\circ} \mathrm{C}$ in a humidified atmosphere containing $5 \% \mathrm{CO} 2$, the scaffolds were covered with additional $800 \mu \mathrm{l}$ of complete medium. Cells grown on tissue culture polystyrene were considered as control. After 24 hours of incubation, samples were cultured in osteogenic medium in order to induce and promote the osteoblastic phenotype expression of MC3T3-E1 cells. The osteogenic medium was obtained by adding the complete $\alpha$-MEM medium with ascorbic acid (0.3 mM) (Quarles et al., 1992) and $\beta$-glycerol phosphate (10 mM) (Wang J. and Yu, 2010). The medium was replaced every $48 \mathrm{~h}$.

The seeding efficiency was calculated $12 \mathrm{~h}$ after the seeding, by trypsinization of the seeded-scaffolds and by counting the cell suspension using hemocytometer counting chamber. The viability and the proliferation of MC3T3-E1 cell line cultured on PHBHHx scaffolds were analysed at day 3, 7, 14 and 21, respectively, by using the WST-1 reagent (Roche), as previously reported (Puppi et al., 2012). Briefly, cell-seeded scaffolds were incubated with the tetrazolium salt that is converted into formazan by mitochondrial dehydrogenases activity in viable cells. The absorbance of the resulting formazan was read at $450 \mathrm{~nm}$ with a reference wavelength of $655 \mathrm{~nm}$. 


\subsubsection{Alkaline phosphatase (ALP) activity measurement}

The differentiation of MC3T3-E1 cells towards the osteoblastic phenotype was evaluated by measuring the alkaline phosphatase activity (ALP) using a colorimetric method. The test is based on the conversion of $p$-nitrophenyl phosphate into $p$ nitrophenol in the presence of the alkaline phosphatase. The seeded scaffolds were treated as previously reported (Puppi et al., 2012). Briefly, scaffolds were washed with DPBS and then placed into $1 \mathrm{ml}$ of lysis buffer with a $\mathrm{pH} 10$. The scaffolds were then submitted to three freeze-thaw cycles for at least one hour for each cycle (Wutticharoenmongkol et al., 2007, Wang J. and Yu, 2010). Following this treatment, supernatant was taken from the samples and added to $p$-nitrophenyl phosphate substrate (Sigma). A standard calibration was prepared using alkaline phosphatase from bovine kidney (Sigma). The reaction was performed at $37^{\circ} \mathrm{C}$ during 30 minutes and the absorbance was read at $405 \mathrm{~nm}$. The results of ALP assay were normalized with the total protein content of each sample, which was measured using a micro BCA protein assay (Pierce) and were reported as nano-moles (nmol) of substrate converted into product per (minute and $\mathrm{mg}$ of protein $)^{-1}$.

\subsection{Statistical analysis}

All the in vitro biological tests were performed on triplicate samples for each kind of scaffold. Quantitative data were presented as mean \pm standard deviation (SD). Statistical difference was analysed using one-way analysis of variance (ANOVA), and a $p<0.05$ (*) and $\mathrm{p}<0.001(* *)$ were considered significant (Soper, 2012). 


\section{Results and Discussion}

In this study, an AM technique previously employed for the development of PCL-based scaffolds (Puppi et al., 2012, Mota et al., 2013) was investigated for the fabrication of layer-by-layer of PHBHHx 3D scaffolds composed by wet-spun fibres. The processing conditions for the manufacturing of different scaffold architectures were optimized and the developed scaffolds were characterized for their morphology, compressive mechanical properties and in vitro cytocompatibility.

\subsection{Study on processing parameters and morphology of PHA scaffolds}

In order to optimize the solution extrusion process, different processing parameters were investigated, such as solvent/non-solvent system and polymer concentration. Combinations between two different solvents (tethrahydrofuran and chloroform) and three different non-solvents (methanol, ethanol and water) were tested by varying polymer concentrations $(5-30 \% \mathrm{w} / \mathrm{v})$. The best results in terms of solution filament coagulation for the formation of a uniform, continuous fibre were achieved employing a $25 \% \mathrm{w} / \mathrm{v}$ PHBHHx solution in chloroform that was extruded in an ethanol coagulation bath. Employing this solvent/non-solvent system, the processing parameters (e.g. $d_{z}, F$ and $\mathrm{V}_{\mathrm{dep}}$ ) for the fabrication of 3D scaffolds layer-by-layer were optimized. For instance, keeping constant all the other optimized parameters, by decreasing $d_{z}$ from $200 \mu \mathrm{m}$ to $100 \mu \mathrm{m}$, it was possible to maintain constant the distance between the needle tip and the last built layer, achieving a better degree of fibre alignment. Indeed, too large $d_{z}$ caused an increase in needle tip-layer distance along with time, resulting in 
"wavelike" deposition (Figure 3a vs. Figure 3b) because of the drag action of the liquid. In addition, a $\mathrm{d}_{\mathrm{z}}$ of $100 \mu \mathrm{m}$ allowed the obtainment of enhanced fusion at the fibre-fibre contact points that led to the formation of a cohesive 3D structure.
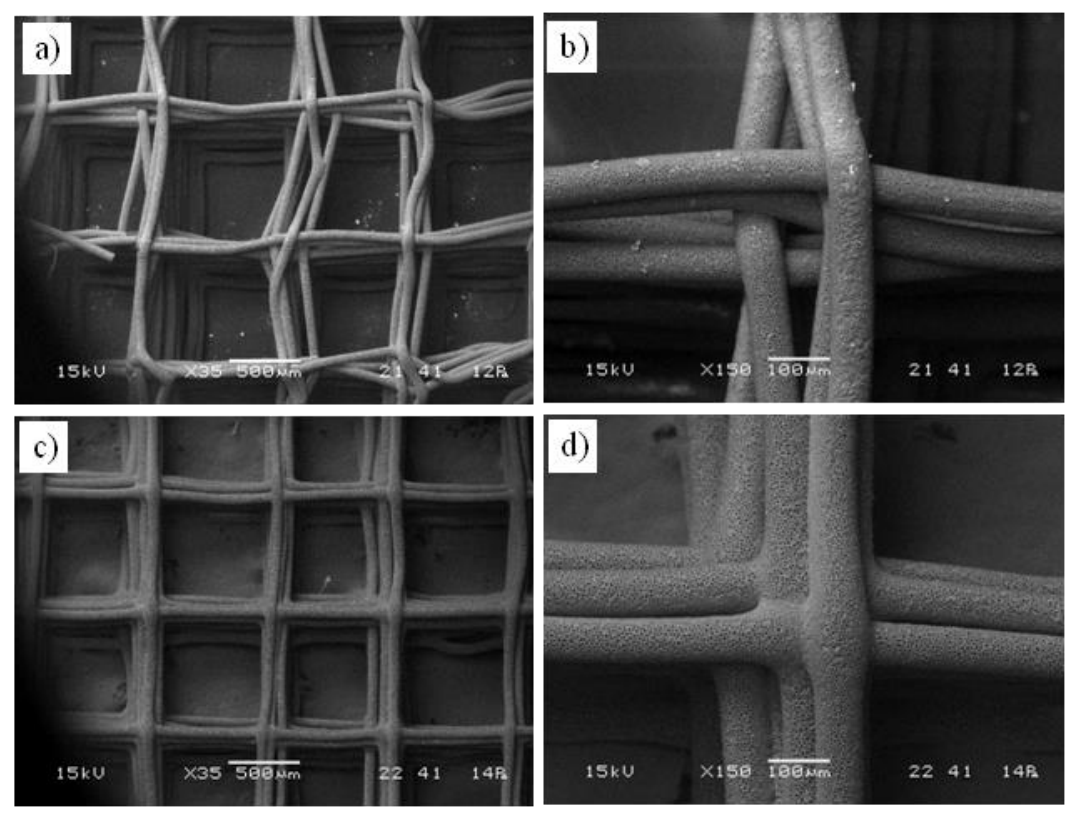

Figure 3 - Representative SEM micrographs of scaffolds obtained applying different $\mathrm{d}_{\mathrm{z}}: 200 \mu \mathrm{m}(\mathrm{a}, \mathrm{b})$ and $100 \mu \mathrm{m}(\mathrm{c}, \mathrm{d})$. (b) and (d) are detailed micrographs of the fibrefibre contact points of (a) and (c), respectively.

Applying the optimized processing parameters $\left(\mathrm{d}_{\mathrm{z}}, \mathrm{F}\right.$ and $\left.\mathrm{V}_{\mathrm{dep}}\right)$ (Table 1), PHBHHx 3D scaffolds with different $\mathrm{d}_{2}(1000 \mu \mathrm{m}, 500 \mu \mathrm{m}$ and $200 \mu \mathrm{m})$ and lay-down pattern $\left(0-45^{\circ}\right.$ and $0-90^{\circ}$ ) were successfully fabricated with a layer-by-layer approach (Figure 2c). 
Table 1 - Design and processing parameters for the fabrication of PHBHHx scaffolds with different architecture.

\begin{tabular}{ccccc}
\hline & \multicolumn{2}{l}{ Design parameters } & \multicolumn{2}{c}{ Processing parameters } \\
\hline Lay-down pattern & $\begin{array}{c}\mathrm{d}_{2}{ }^{(*)} \\
{[\mu \mathrm{m}]}\end{array}$ & $\begin{array}{c}\mathrm{d}_{\mathrm{z}}{ }^{(*)} \\
{[\mu \mathrm{m}]}\end{array}$ & $\begin{array}{c}\mathrm{F}^{(*)} \\
{\left[\mathrm{ml} \cdot \mathrm{h}^{-1}\right]}\end{array}$ & $\begin{array}{c}\mathrm{V}_{\text {dep }}{ }^{(*)} \\
{\left[\mathrm{mm} \cdot \mathrm{min}^{-1}\right]}\end{array}$ \\
\hline $0-90^{\circ}$ & 1000 & 100 & 0.5 & 600 \\
& 500 & 100 & 0.5 & 600 \\
$0-45^{\circ}$ & 200 & 100 & 0.3 & 600 \\
\hline
\end{tabular}

$(*) d_{2}=$ distance between fibre axis within the same layer; $d_{z}=$ inter-layer needle translation; $\mathrm{F}=$ solution feed rate; $\mathrm{V}_{\text {dep }}=$ deposition velocity.

The developed 3D scaffolds were rectangular prism-shaped samples composed by the same number of layers but different thickness depending on internal architecture. SEM analysis showed that the reproducibility of internal architecture and the degree of fibre alignment were enhanced by decreasing $d_{2}$ (Figure 4 ). In addition, the fibres composing the scaffolds presented a highly porous morphology both on the outer surface and in the cross-section with a pore size of a few micrometres (insert micrographs in Figure 4). 

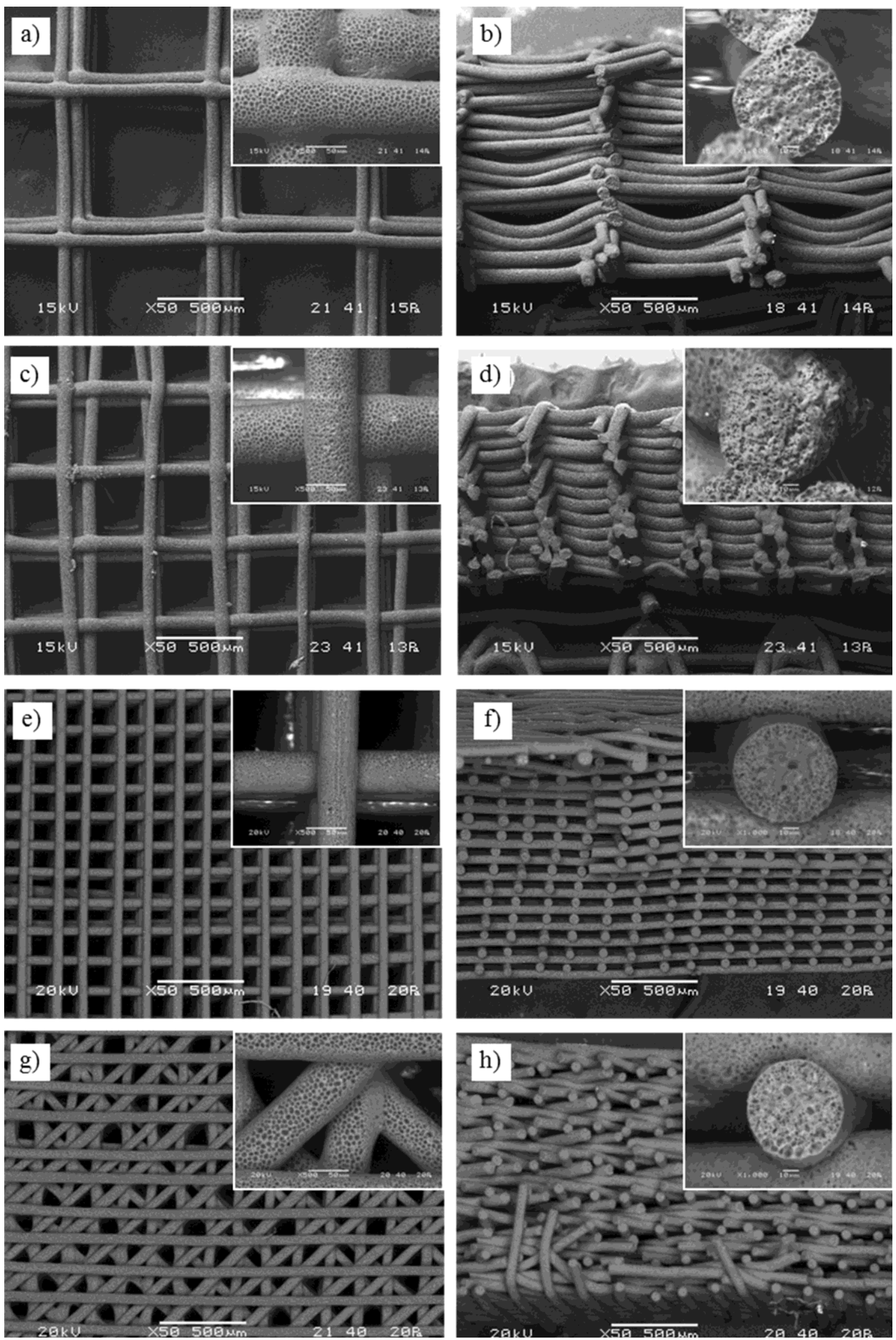
Figure 4 - Representative top view and cross-section micrographs of PHBHHx scaffolds: (a, b) $0-90^{\circ}$ pore and $\mathrm{d}_{2}=1000 \mu \mathrm{m}$; (c, d) 0-90 pore and $\mathrm{d}_{2}=500 \mu \mathrm{m} ;(\mathrm{e}, \mathrm{f})$ $0-90^{\circ}$ pore and $\mathrm{d}_{2}=200 \mu \mathrm{m} ;(\mathrm{g}, \mathrm{h}) 0-45^{\circ}$ pore and $\mathrm{d}_{2}=200 \mu \mathrm{m}$. Insert micrographs are detail of the fibre-fibre contact regions ( $\mathrm{a}, \mathrm{c}, \mathrm{e}$ and $\mathrm{g}$ ) and single fibre cross-section (b, $\mathrm{d}$, f and $h$ ).

The sponge-like morphology of the scaffolds is due to the solvent/non-solvent counterdiffusion during polymer solution coagulation that leads to a separation into a polymerrich and a polymer-poor phase, as discussed in previous studies (Puppi et al., 2012, Mota et al., 2013). A number of studies on PHAs scaffolds have shown that surface porosity and roughness influence cell adhesion and proliferation (Wang Y. W. et al., 2004, Wang Y. W. et al., 2005a, Wang Y. W. et al., 2005b, Ji et al., 2008, Wang L. et $a l ., 2010)$. The highly porous morphology of the fibres constituting the developed scaffolds can present some advantages in influencing the biodegradation rate, the mass transfer associated to cell metabolism and the mechanisms regulating cell adhesion and proliferation (Karageorgiou and Kaplan, 2005, Puppi et al., 2012).

Cross-section micrographs of the scaffolds designed with $\mathrm{d}_{2}=1000$ or $500 \mu \mathrm{m}$ showed limited porosity along $\mathrm{Z}$ axis likely due to the slow solidification of the depositing fibre (Figures $4 \mathrm{~b}$ and $4 \mathrm{~d}$ ). However, by decreasing $\mathrm{d}_{2}$ to $200 \mu \mathrm{m}$ a well-defined porosity in the cross-section was observed for both lay-down patterns $\left(0-90^{\circ}\right.$ and $\left.0-45^{\circ}\right)$ (Figures $4 f$ and 4h). As shown in Table 2, the fibre diameter was in the range of tens of micrometres and it significantly decreased when $\mathrm{d}_{2}$ decreased to $200 \mu \mathrm{m}$, likely because of the lower F employed. Pore size in the X, Y plane decreased significantly in the range $800-100 \mu \mathrm{m}$ when $\mathrm{d}_{2}$ was decreased. The differences between the set $\mathrm{d}_{2}(1000$, 
500 or $200 \mu \mathrm{m}$ ) and the measured $d_{2}$ (obtained by the analysis of $d_{1}$ and $X, Y$ pore size) values were likely related to the shrinking of the polymeric structure during solidification and to the liquid drag forces acting on the solidifying filament before it reaches the previously deposited layer. Pore size along $\mathrm{Z}$ axis was only measurable in the case of scaffolds designed with $\mathrm{d}_{2}$ of $200 \mu \mathrm{m}$ and was $45 \pm 4 \mu \mathrm{m}$ and $31 \pm 5 \mu \mathrm{m}$ for 0 $90^{\circ}$ and $0-45^{\circ}$, respectively.

Table 2 - Architectural parameters of PHBHHx scaffolds

\begin{tabular}{ccccccc}
\hline $\begin{array}{c}\text { Pore } \\
\text { Architecture }\end{array}$ & $\begin{array}{c}\mathrm{d} 2 \\
{[\mu \mathrm{m}]}\end{array}$ & $\begin{array}{c}\mathrm{d} 1 \\
{[\mu \mathrm{m}]}\end{array}$ & $\begin{array}{c}\text { Pore Size } \\
(\mathrm{X}, \mathrm{Y} \text { plane }) \\
{[\mu \mathrm{m}]}\end{array}$ & $\begin{array}{c}\text { Pore Size } \\
(\mathrm{Z} \text { axis }) \\
{[\mu \mathrm{m}]}\end{array}$ & $\begin{array}{c}\text { Porosity } \\
(\text { Theor. }) \\
{[\%]}\end{array}$ & $\begin{array}{c}\text { Porosity } \\
(\mathrm{DSC}) \\
{[\%]}\end{array}$ \\
\hline $0-90^{\circ}$ & 1000 & $71.9 \pm 3.3$ & $\begin{array}{c}789.0 \pm 10.8 \\
(*)\end{array}$ & $/$ & 88.4 \\
\hline $0-90^{\circ}$ & 500 & $76.0 \pm 8.8$ & $\begin{array}{c}357.1 \pm 52.5 \\
(*)\end{array}$ & $/$ & $/$ & 79.4 \\
\hline $0-90^{\circ}$ & 200 & $\begin{array}{c}47.2 \pm 5.0 \\
\left(* \text { vs d } \mathrm{d}_{2}=500\right. \\
\text { and } 1000)\end{array}$ & $\begin{array}{c}123.0 \pm 20.1 \\
(*)\end{array}$ & $\begin{array}{c}45.3 \pm 4.1 \\
(*)\end{array}$ & 77.8 & 78.6 \\
\hline $0-45^{\circ}$ & 200 & $\begin{array}{c}56.2 \pm 4.1 \\
(* \text { vs d } 2=500 \\
\text { and } 1000)\end{array}$ & $\begin{array}{c}115.9 \pm 19.5 \\
(*)\end{array}$ & $\begin{array}{c}31.1 \pm 5.2 \\
(*)\end{array}$ & 60.1 & \\
\hline
\end{tabular}

$\mathrm{d}_{1}=$ fibre diameter; $\mathrm{d}_{2}=$ designed distance between fibre axis.

(*) parameter significantly different $(\mathrm{p}<0.05)$.

As shown by high magnification SEM micrographs of the external fibre surface, the scaffolds obtained with $\mathrm{d}_{2}=200 \mu \mathrm{m}$ and $0-90^{\circ}$ lay-down pattern (Figure $4 \mathrm{e}$ ) were characterized by a less porous morphology of the single fibres in comparison to scaffolds obtained with $d_{2}$ of 500 and $1000 \mu \mathrm{m}$ (Figure 4a and 4c). This morphological difference may be due to the different $F$ employed, which can affect the coagulation rate as well as the stretching force acting on the solidifying filament caused by the translation of the needle and the construction platform. In addition, the fibres of $0-45^{\circ}$ lay-down pattern scaffolds (Figure $4 \mathrm{~g}$ ) appear to be more porous in comparison to the fibres of scaffolds obtained with $\mathrm{d}_{2}=200 \mu \mathrm{m}$ and $0-90^{\circ}$ lay-down pattern. Since all the 
other processing conditions were the same, this morphological difference might be related to the different movement of the needle and of the construction platform, which can affect different factors influencing fibre morphology formation, such as the fluid motion conditions in the coagulation bath as well as the drag and stretching forces acting on the coagulating filament. The observed increase in porosity could be also attributed to an influence on the coagulation process of the larger contact area between the deposited solidifying filament and the previously deposited layer in $0-45^{\circ}$ compared to $0-90^{\circ}$ lay-down pattern scaffolds (Moroni et al., 2006). This factor may explain also the more pronounced fibre flattening effect at the fibre-fibre intersection points observed in $0-45^{\circ}$ pore scaffolds, leading to a significantly lower $\mathrm{d}_{3}$ value (table 2 ).

Although in the last years a number of articles have explored the development of PHBHHx porous structures as potential scaffolds for tissue engineering (Wang Y. W. et al., 2004, Wang Y. W. et al., 2005a, Jing et al., 2008a, Wang Y et al., 2012), this is the first study reporting on the fabrication of PHBHHx scaffolds with an AM approach. In addition, the versatility of the employed computer-aided wet-spinning technique in terms of structural parameters control was better highlighted in this study. It was possible to produce scaffolds with a different lay-down pattern $\left(0-45^{\circ}\right)$ and smaller pore size (down to $115 \mu \mathrm{m}$ ) and fibre diameter (down to $47 \mu \mathrm{m}$ ) when compared to previous studies employing the same fabrication technique (Puppi et al., 2012, Mota et al., 2013). Melt-electrospinning writing technique is allowing to obtain similar layered assemblies of aligned polymeric fibres with a better resolution of the structural elements (fibre diameters of tens down to $5 \mu \mathrm{m}$ ) and the advantage of avoiding the use of organic solvents (Dalton et al., 2013). On the other hand, the wet-spinning technique is suited for the processing of a broader range of polymeric materials from natural and synthetic 
resources (Tuzlakoglu and Reis, 2008, Puppi et al., 2011b) in comparison to the limited number of polymers with thermoplastic behaviour suitable for melt processing. In addition, as demonstrated by the large volume of published studies on microfibers biofunctionalization with different bioactive agents, such as antibiotics, glycosaminoglycans, proteins, growth factors, genes and viruses (Mathiowitz et al., 2013), wet-spun fibers turned out to have tremendous potential in the design of controlled-release scaffolds due to their diverse release profiles, easy loading by simple methods (e.g. direct solution blending) and the avoiding of thermal denaturation of therapeutics unlike melt-spinning.

\subsection{PHA scaffolds porosity}

The porosity of scaffolds was estimated using two methods: one following a theoretical approach considering the architectural parameters obtained from SEM micrographs analysis (Equation 5), and the other one based on the crystallinity of polymeric scaffolds assessed by DCS analysis (Equation 6).

As previously discussed, the scaffolds with $\mathrm{d}_{2}$ of $500 \mu \mathrm{m}$ or $1000 \mu \mathrm{m}$ were characterized by a limited porosity in the cross-section that did not allow to apply the theoretical approach. The calculated porosity using the crystalline degree method was $88.4 \%$ for samples with $\mathrm{d}_{2}=1000 \mu \mathrm{m}$ and $84.4 \%$ for samples with $\mathrm{d}_{2}=500 \mu \mathrm{m}$ (Table2). The scaffolds with a designed $\mathrm{d}_{2}$ of $200 \mu \mathrm{m}$ and $0-90^{\circ}$ pore geometry showed a welldefined porous structure both on the top view and cross-section, and the theoretical approach could be applied with a good level of confidence. In this case, the theoretical porosity was $77.8 \%$ and the corresponding value obtained by using the method based on the crystalline degree was $79.1 \%$. This difference could be related to the porosity of the 
single fibre that was not considered in the theoretical approach. Indeed, as previously discussed, SEM micrographs revealed that the fibres composing the scaffold presented a porous structure typical of delayed solvent/non-solvent demixing. For scaffolds with $\mathrm{d}_{2}=200 \mu \mathrm{m}$ and $0-45^{\circ}$ pore geometry the theoretical porosity was $60 \%$ while the porosity calculated with the crystalline degree approach was $78.6 \%$. This marked difference is likely due to the highly porous morphology of the single fibres (Figures $4 \mathrm{~g}$ and $4 \mathrm{~h}$ ), which was not considered in the first approach, as well as to significant errors in the measurement of $d_{3}$ due to the high packing density structure in $0-45^{\circ}$ lay-down pattern scaffolds (Figure 4h).

\subsection{Compressive mechanical characterization of PHA scaffolds}

The mechanical compression tests were performed to assess the mechanical properties of PHBHHx scaffolds composed of 50 overlapped layers and with different $d_{2}$ (500 or $200 \mu \mathrm{m})$ and pore geometry $\left(0-90^{\circ}\right.$ and $\left.0-45^{\circ}\right)$. The compressive modulus, stress and strain at yield are reported in Table 3.

Table 3 - Compressive mechanical properties of PHBHHx scaffolds with different $\mathrm{d}_{2}$ and pore architecture.

\begin{tabular}{cccc}
\hline $\begin{array}{c}\text { Scaffold properties } \\
\left(\mathrm{d}_{2} ; \text { pore architecture }\right)\end{array}$ & $\begin{array}{c}\text { Compressive modulus } \\
{[\mathrm{MPa}]}\end{array}$ & $\begin{array}{c}\text { Yielding Stress } \\
{[\mathrm{MPa}]}\end{array}$ & $\begin{array}{c}\text { Yielding Strain } \\
{[\%]}\end{array}$ \\
\hline $500 \mu \mathrm{m} ; 0-90^{\circ}$ & $0.71 \pm 0.11$ & $0.39 \pm 0.01$ & $37 \pm 3$ \\
$200 \mu \mathrm{m} ; 0-90^{\circ}$ & $1.40 \pm 0.27$ & $0.49 \pm 0.07$ & $39 \pm 6$ \\
$200 \mu \mathrm{m} ; 0-45^{\circ}$ & $0.84 \pm 0.06$ & $0.46 \pm 0.004$ & $39 \pm 0$ \\
\hline
\end{tabular}


Regarding scaffolds with $0-90^{\circ}$ pore architecture, those with smaller $\mathrm{d}_{2}(200 \mu \mathrm{m})$ showed higher compressive modulus and stress at yield, with a small increase in the strain at yield. When comparing scaffolds with $\mathrm{d}_{2}$ of $200 \mu \mathrm{m}$, the compressive modulus increased significantly from $0.84 \mathrm{MPa}$ for $0-45^{\circ}$ pore architecture to $1.40 \mathrm{MPa}$ for $0-90^{\circ}$ architecture, while the stress and strain at yield were similar for the two pore architectures. Scaffolds with $0-90^{\circ}$ architecture and $\mathrm{d}_{2}=200 \mu \mathrm{m}$ presented the highest compressive modulus and yielding stress, likely because of their higher fibre packing density as well as their higher fibre-fibre intersection points density. Regarding the scaffolds with $0-45^{\circ}$ architecture, even if the fibre-fibre contact area is larger than in 0 $90^{\circ}$ architecture, the fibre-fibre intersection points are not aligned, which reflects in lower compressive modulus as previously reported by Moroni et al (Moroni et al., 2006).

The stress-strain curves (Figure 5) showed an initial linear region followed by a plateau and a subsequent region of increasing slope. As discussed in previous articles investigating the mechanical behaviour of porous scaffold structures fabricated by AM techniques (Zein et al., 2002, Domingos et al., 2012, Mota et al., 2013), the linear region is likely due to the response of the fibre-fibre contact points to the applied deformation, the subsequent plateau region to the collapse of the pore network and the final increase of the compressive stress to a further densification of the scaffold structure. 


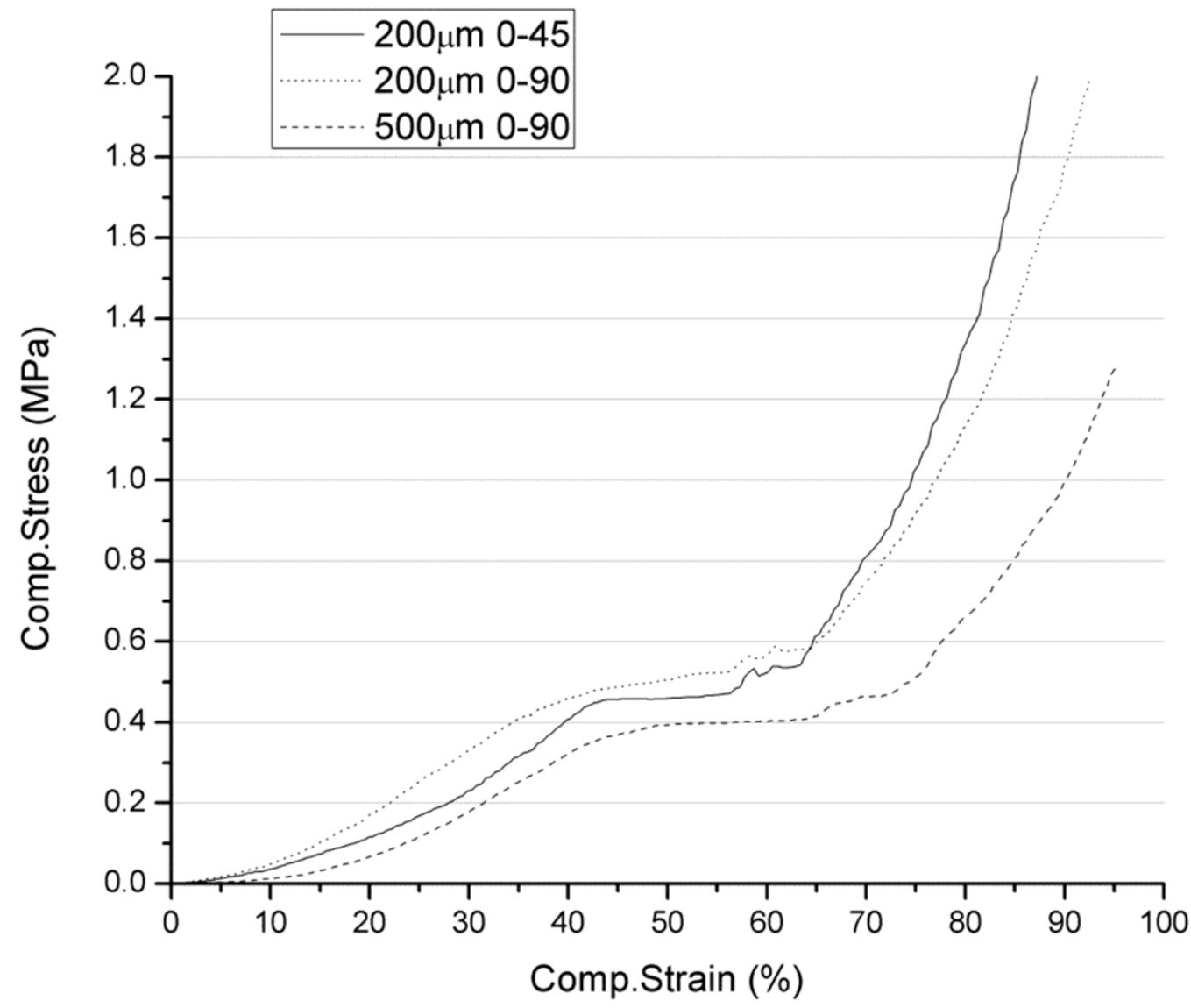

Figure 5 - Representative stress-strain compression curves of different PHBHHx scaffolds.

A scaffold should have suitable mechanical properties during in vitro cell culture to maintain the structural integrity while cell in-growth and extracellular matrix formation occur. Moreover, scaffolds should maintain structural stability while handled by physicians during the implantation phase, and should match closely the mechanical properties of the host tissue capable of bearing in vivo stresses and loading (Kohane and Langer, 2008, Puppi et al., 2010). Besides chemical composition, various structural parameters on different scale levels (e.g. 3D shape and size, overall porosity, architecture of the dense phase, and pores geometry, size, distribution and 
interconnection) determine the overall mechanical response of a 3D porous scaffold (Fang et al., 2005, Moroni et al., 2006, Puppi et al., 2010). The developed PHBHHx scaffolds showed higher compressive modulus in comparison to other PHAs scaffolds with a different porosity and porous architecture obtained by means of salt leaching (Wang Y. W. et al., 2005a) or freeze-drying (Jing et al., 2008b). In addition, they showed higher yield strength and comparable compressive modulus in comparison to PCL-based layered scaffolds with a similar internal architecture and produced using the same computer-controlled wet-spinning technique (Puppi et al., 2012, Mota et al., 2013). However, the mechanical properties of the developed PHBHHx scaffolds are still far from those of load-bearing bone tissues. A possible strategy to enhance their mechanical performance envisages the loading of a bioactive ceramic (e.g. hydroxyapatite) into the wet-spun fibres, as previously demonstrated (Mota et al., 2013).

\subsection{Biological evaluation of PHA scaffolds}

\subsubsection{Cell viability and proliferation}

Biological investigations of the prepared PHBHHx scaffolds were carried out in order to evaluate their ability to sustain MC3T3-E1 cell viability and proliferation. The seeding efficiency was calculated 12 hours after the seeding procedure. The scaffolds with $\mathrm{d}_{2}$ of $200 \mu \mathrm{m}$ showed a significantly higher $(\mathrm{p}<0.05)$ seeding efficiency $(32.2 \pm 2.0 \%$ and $35.5 \pm 2.6 \%$ for $0-90^{\circ}$ and $0-45^{\circ}$ geometry, respectively) in comparison to the scaffolds with $\mathrm{d}_{2}$ of $500 \mu \mathrm{m}(28.3 \pm 1.3 \%)$. These results are in agreement with previous studies 
reporting on significant effects of scaffolds pore size on the seeding efficiency (Sobral et al., 2011).The relatively low seeding efficiency was probably due to the width between fibres, that do not retain a high number of cells during the seeding procedure. Quantitative evaluation of cell proliferation was performed at each endpoint. The results showed the presence of viable cells on each typology of constructs since day 3 of culture, with a poor cell proliferation during the first two weeks of culture but with an increasing peak at day 21 (Figure 6).

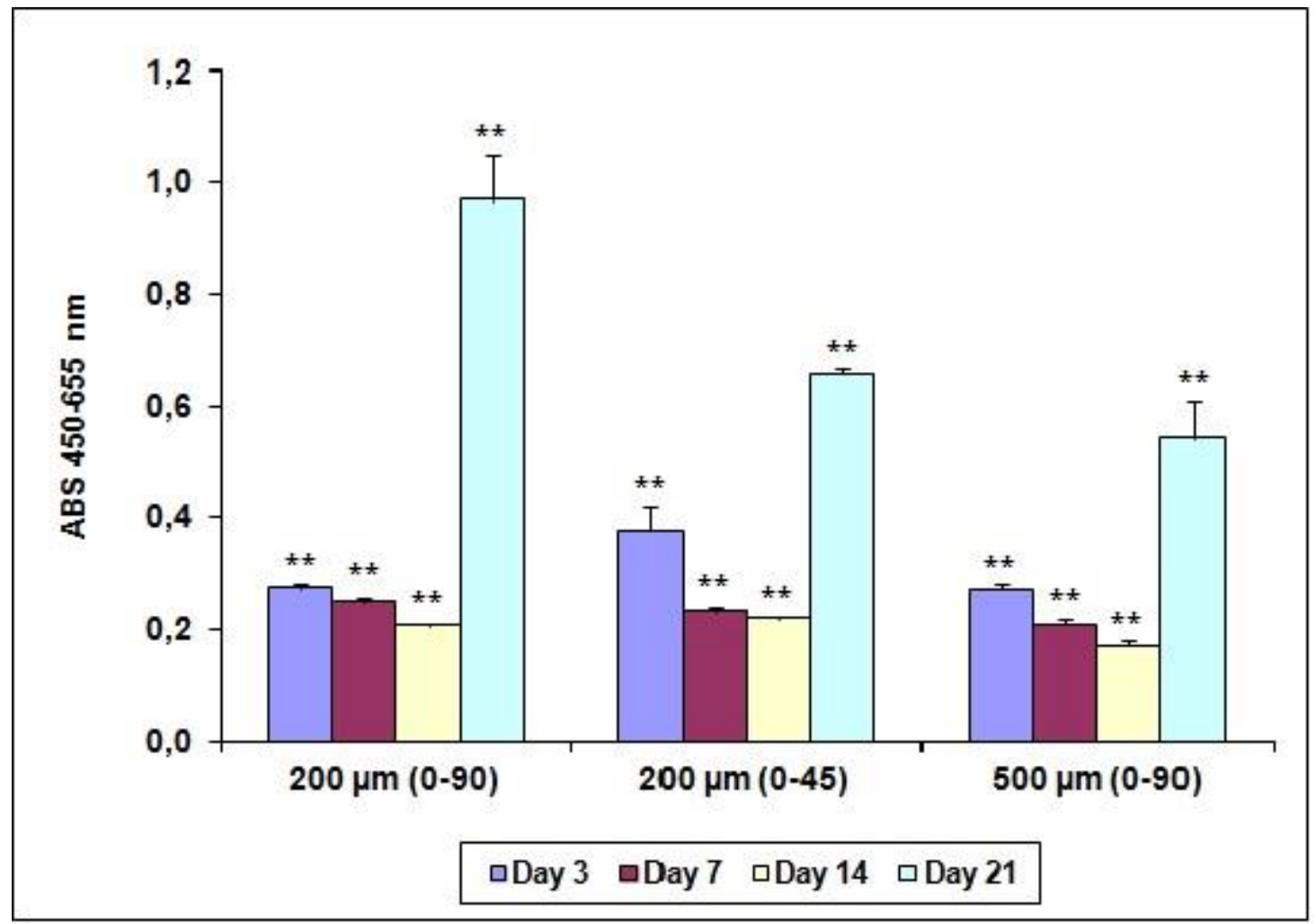

Figure 6 - Cell proliferation of MC3T3-E1 grown on PHBHHx scaffolds (WST-1 assay). ** significantly different $(\mathrm{p}<0.001)$ in comparison with other scaffold typologies at the same endpoint.

Cell proliferation delay could be attributed to the interconnected structure of the scaffolds that did not permit a wide colonization during the seeding procedure, as well 
as to the surface properties of PHBHHx that influenced the early stages of cell attachment, spreading and growth (Wang Y. W. et al., 2004). The surface characteristics are important criteria to judge the biocompatibility of a biomaterial and are influenced by many properties of the biomaterials, including surface composition, surface free energy and morphology. The process of cell attachment is mainly directed by physical and chemical interactions between material and cells. In fact, data from the literature (Li J. et al., 2005) suggests that the adhesion properties of PHBHHx improve with increases in surface porosity and roughness. Nevertheless, despite an initial poor cell proliferation, at day 21 of culture MC3T3-E1 cells reached appreciable values of cell proliferation for all the typologies of PHBHHx scaffolds, confirming data from the literature on the biocompatibility of the material (Wang Y. W. et al., 2005b). Statistical studies highlighted significant differences in the values of cell proliferation $(p<0.001)$ comparing the three typologies of scaffolds during each endpoint. In particular, the 200 $\mu \mathrm{m}\left(0-90^{\circ}\right)$ construct displayed the most promising geometry for a significant cell adhesion and proliferation.

\subsubsection{Alkaline phosphatase (ALP) activity measurement}

ALP, as bone isoform, is known to be involved in the metabolism of the phosphates (Beck et al., 1998) and is considered an early indicator of osteogenesis. ALP activity was measured to determine the occurred MC3T3-E1 pre-osteoblast differentiation (Calvert et al., 2005, Orimo, 2010).

Results showed that MC3T3-E1, cultured on all architectures of PHBHHx scaffolds, produced low levels of ALP during the first three endpoints of analysis, with an increase observed at day 21 (Figure 7). This behaviour, in accordance with the proliferation 
trend, could be justified by the need for the MC3T3-E1 to reach an adequate cell confluence on the 3D constructs prior to the expression of high levels of ALP, a marker of the mature osteoblast function (Quarles et al., 1992, Wutticharoenmongkol et al., 2007, Park J. B., 2012). In fact, the peak of proliferation on day 21 (Figure 6), with an ensuing shift in cell maturation levels towards early differentiation stages, was confirmed by an increase in ALP activity at day 21 for all the typologies of PHBHHx scaffolds (St-Pierre et al., 2005, Murphy et al., 2010, Van Bael et al., 2012). Moreover, statistical studies showed significant differences in the values of ALP for the three typologies of scaffolds at days 7 and $14(\mathrm{p}<0.05)$ and at day $21(\mathrm{p}<0.001)$. However, the detected ALP levels confirmed good osteogenesis properties for all types of PHBHHx scaffolds, as reported in previous studies (Wang Y. W. et al., 2005a) and in particular for the $500 \mu \mathrm{m}\left(0-90^{\circ}\right)$ geometry.

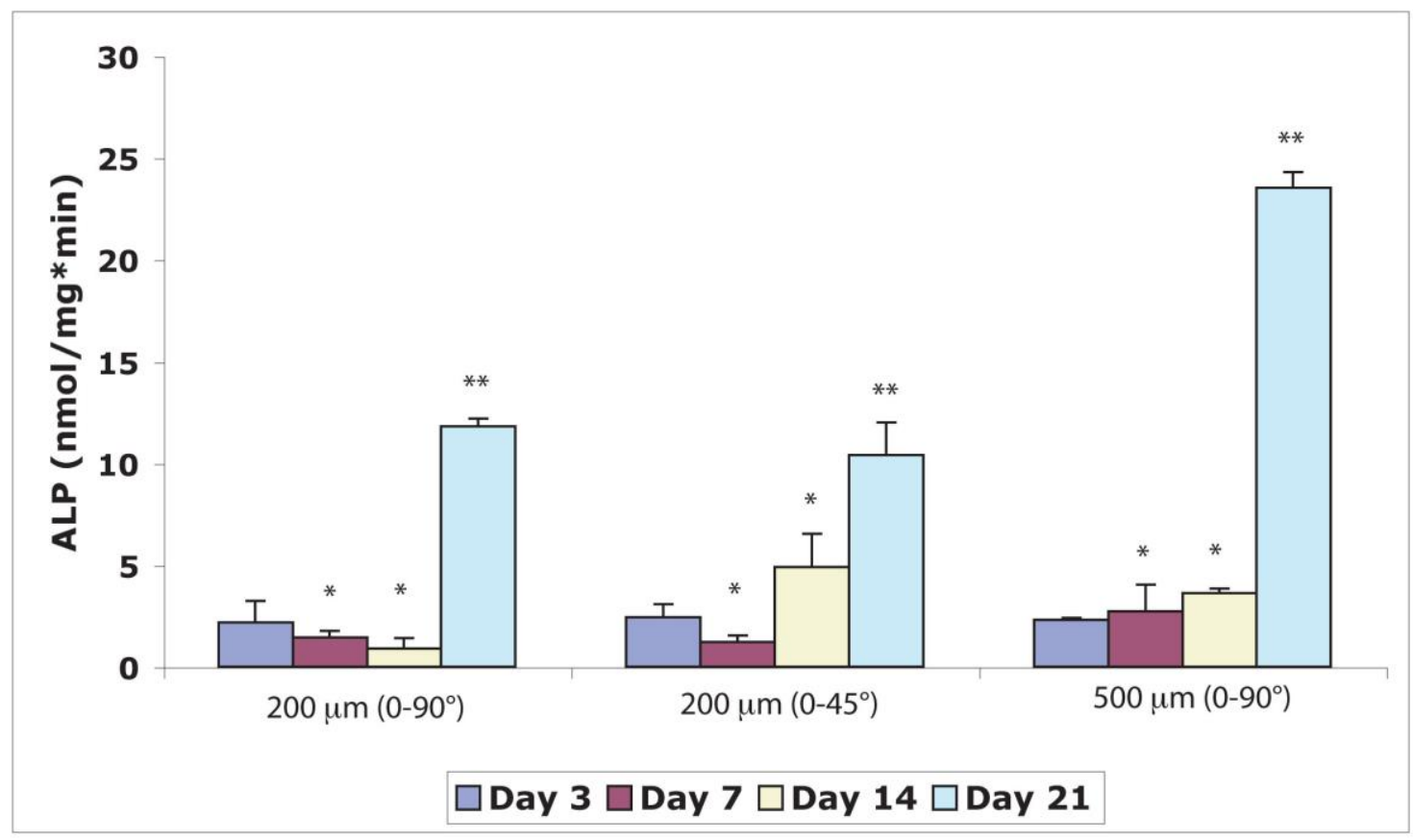


Figure 7 - ALP activity on MC3T3-E1 cells cultured on PHBHHx based scaffolds. ** $(\mathrm{p}<0.001)$ and $*(\mathrm{p}<0.05)$ significantly different in comparison with the other scaffold typologies at the same endpoint.

\section{Conclusions}

This is the first study showing the possibility of using AM for the fabrication of scaffolds made of PHBHHx with a good control over scaffold external shapes and internal architectures. PHBHHx 3D scaffolds with different pore sizes and architectures were fabricated layer-by-layer by means of a computer-controlled wet-spinning system. The resulting scaffolds were composed of aligned fibres with a highly porous morphology both in the cross-section and in the outer surface. In addition, they presented enhanced compressive properties in comparison to PHAs scaffolds fabricated by means of other techniques reported on previous studies. PHBHHx scaffolds also demonstrated good cytocompatibility as they were able to sustain murine pre-osteoblast proliferation and differentiation toward an osteoblastic phenotype.

\section{Acknowledgement}

The present paper reports on the work performed within the EC-funded project "Hyanji Scaffold" in the People Program of the 7FP by exploiting the expertise in that topic acquired in the implementation of the EC-funded project: NoE Expertissues "NMP3CT-2004-500283". The financial supports provided by EC under the Contract "PIRSES-GA-2008-230791" and hence for Expertissues project are gratefully acknowledged. 


\section{References}

Beck GR, Sullivan EC, Moran E, Zerler B. 1998, Relationship between alkaline phosphatase levels, osteopontin expression, and mineralization in differentiating MC3T3-E1 osteoblasts, J Cell Biochem, 68: 269-280.

Calvert JW, Chua WC, Gharibjanian NA, Dhar S, Evans GRD. 2005, Osteoblastic Phenotype Expression of MC3T3-E1 Cells Cultured on Polymer Surfaces, Plastic and Reconstructive Surgery, 116: 567-576.

Chen GQ, Wu Q. 2005, The application of polyhydroxyalkanoates as tissue engineering materials, Biomaterials, 26: 6565-6578.

Chen GQ, Wu Q, Xi J, Yu HP. 2000, Microbial production of biopolyesterspolyhydroxyalkanoates, Progress in natural science, 10: 843-850.

Chen GQ, Zhang G, Park SJ, Lee SY. 2001, Industrial scale production of poly(3hydroxybutyrate-co-3-hydroxyhexanoate), Appl Microbiol Biotechnol, 57: 50-55.

Cheng S, Wu Q, Yang F, Xu M, Leski M, Chen GQ. 2005, Influence of DL-betahydroxybutyric acid on cell proliferation and calcium influx, Biomacromolecules, 6: 593-597.

Clyne AM. 2011, Thermal Processing of Tissue Engineering Scaffolds, J Heat Transfer, 133: 034001-034008.

Dalton PD, Vaquette C, Farrugia BL, Dargaville TR, Brown TD, Hutmacher DW. 2013, Electrospinning and additive manufacturing: converging technologies, Biomaterials Science, 1: 171-185.

Doi Y, Kitamura S, Abe H. 1995, Microbial Synthesis and Characterization of Poly(3hydroxybutyrate-co-3-hydroxyhexanoate), Macromolecules, 28: 4822-4828.

Domingos M, Chiellini F, Gloria A, Ambrosio L, Bartolo P, Chiellini E. 2012, Effect of process parameters on the morphological and mechanical properties of 3D Bioextruded poly(E-caprolactone) scaffolds, Rapid Prototyping Journal, 18: 56-67.

Doyle C, Tanner ET, Bonfield W. 1991, In vitro and in vivo evaluation of polyhydroxybutyrate and of polyhydroxybutyrate reinforced with hydroxyapatite, Biomaterials, 12: 841-847.

EU project: Wheypol "Dairy Industry Waste as Source for Sustainable Polymeric Material Production" G5RD-CT-2001-00591.

EU project: Polyver "Production of Polyhydroxyalkanoates from Olive Oil Mills Wastewater" COOP-CT-2006-032967.

EU project: Animpol "Biotechnological conversion of carbon containing wastes for eco-efficient production of high added value products", GA 245084.

Fang Z, Starly B, Sun W. 2005, Computer-aided characterization for effective mechanical properties of porous tissue scaffolds, Computer-Aided Design, 37: 65-72.

Garcia-Garcia JM, Garrido L, Quijada-Garrido I, Kaschta J, Schubert DW, Boccaccini AR. 2012, Novel poly(hydroxyalkanoates)-based composites containing Bioglass ${ }^{\circledR}$ and calcium sulfate for bone tissue engineering, Biomed Mater, 7: 054105.

Jack KS, Velayudhan S, Luckman P, Trau M, Grøndahl L, Cooper-White J. 2009, The fabrication and characterization of biodegradable HA/PHBV nanoparticle-polymer composite scaffolds, Acta Biomaterialia, 5: 2657-2667.

Ji Y, Li XT, Chen GQ. 2008, Interactions between a poly(3-hydroxybutyrate-co-3hydroxyvalerate-co-3-hydroxyhexanoate) terpolyester and human keratinocytes, Biomaterials, 29: 3807-3814. 
Jing X, Ling Z, Zhenhu An Z, Guoqiang C, Yandao G, Nanming Z, Xiufang Z. 2008a, Preparation and Evaluation of Porous Poly(3-hydroxybutyrate-co-3hydroxyhexanoate) - Hydroxyapatite Composite Scaffolds, J Biomater Appl, 22: 293307.

Jing X, Ling Z, Zhenhu An Z, Guoqiang C, Yandao G, Nanming Z, Xiufang Z. 2008b, Preparation and evaluation of porous poly(3-hydroxybutyrate-co-3-hydroxyhexanoate) hydroxyapatite composite scaffolds, J Biomater Appl, 22: 293-307.

Karageorgiou V, Kaplan D. 2005, Porosity of 3D biomaterial scaffolds and osteogenesis, Biomaterials, 26: 5474-5491.

Ke S, Yang Y, Ren L, Wang Y, Li Y, Huang H. 2012, Dielectric behaviors of PHBHHx-BaTiO3 multifunctional composite films, Compos Sci Technol, 72: 370-375.

Kohane DS, Langer R. 2008, Polymeric biomaterials in tissue engineering, Pediatr Res, 63: 487-491.

Köse GT, Korkusuz F, Korkusuz P, Hasirci V. 2004, In Vivo Tissue Engineering of Bone Using Poly(3-hydroxybutyric acid-co-3-hydroxyvaleric acid) and Collagen Scaffolds, Tissue Engineering, 10: 1234-1250.

Landers R, Pfister A, Hübner U, John H, Schmelzeisen R, Mülhaupt R. 2002, Fabrication of soft tissue engineering scaffolds by means of rapid prototyping techniques, J Mater Sci, 37: 3107-3116.

Langer R, Vacanti JP. 1993, Tissue Engineering, Science, 260: 920-926.

Li J, Yun H, Gong YD, Zhao NM, Zhang XF. 2005, Effects of surface modification of poly (3-hydroxybutyrate-co-3-hydroxyhexanoate) (PHBHHx) on physicochemical properties and on interactions with MC3T3-E1 cells, J Biomed Mater Res A, 75A: 985998.

Li XT, Zhang Y, Chen GQ. 2008, Nanofibrous polyhydroxyalkanoate matrices as cell growth supporting materials, Biomaterials, 29: 3720-3728.

Lim J, Chong MSK, Teo EY, Chen G-Q, Chan JKY, Teoh S-H. 2013, Biocompatibility studies and characterization of poly(3-hydroxybutyrate-co-3hydroxyhexanoate)/polycaprolactone blends, J Biomed Mater Res B, 101B: 752-761.

Mathiowitz E, Lavin DM, Hopkins RA. 2013, Wet spun microfibers: potential in the design of controlled-release scaffolds?, Therapeutic Delivery, 4: 1075-1077.

Morelli A, Puppi D, Chiellini F. 2013, Polymers from Renewable Resources, J Renew Mater, 1: 83-112.

Moroni L, de Wijn JR, van Blitterswijk CA. 2006, 3D fiber-deposited scaffolds for tissue engineering: Influence of pores geometry and architecture on dynamic mechanical properties, Biomaterials, 27: 974-985.

Mota C, Puppi D, Chiellini F, Chiellini E. 2012, Additive manufacturing techniques for the production of tissue engineering constructs, J Tissue Eng Regen Med, DOI: 10.1002/term. 1635

Mota C, Puppi D, Dinucci D, Gazzarri M, Chiellini F, Chiellini E. 2013, Additive Manufacturing of Star Poly( $\varepsilon$-caprolactone) Wet-spun Scaffolds for Bone Tissue Engineering Applications, J Bioact Compat Pol, 28: 320-340.

Murphy CM, Haugh MG, O'Brien FJ. 2010, The effect of mean pore size on cell attachment, proliferation and migration in collagen-glycosaminoglycan scaffolds for bone tissue engineering, Biomaterials, 31: 461-466.

Nebe B, Forster C, Pommerenke H, Fulda G, Behrend D, Bernewski U, Schmitz K-P, Rychly J. 2001, Structural alterations of adhesion mediating components in cells cultured on poly-beta-hydroxy butyric acid, Biomaterials, 22: 2425-2434. 
Orimo H. 2010, The mechanism of mineralization and the role of alkaline phosphatase in health and disease, J Nippon Med Sch, 77: 4-12.

Park JB. 2012, The effects of dexamethasone, ascorbic acid, and beta-glycerophosphate on osteoblastic differentiation by regulating estrogen receptor and osteopontin expression, J Surg Res, 173: 99-104.

Park SA, Lee SH, Kim WD. 2011, Fabrication of porous polycaprolactone/hydroxyapatite (PCL/HA) blend scaffolds using a 3D plotting system for bone tissue engineering, Bioprocess Biosyst Eng, 34: 505-513.

Puppi D, Chiellini F, Piras AM, Chiellini E. 2010, Polymeric materials for bone and cartilage repair, Progress in Polymer Science, 35: 403-440.

Puppi D, Piras AM, Chiellini F, Chiellini E, Martins A, Leonor IB, Neves N, Reis R. 2011a, Optimized electro- and wet-spinning techniques for the production of polymeric fibrous scaffolds loaded with bisphosphonate and hydroxyapatite, J Tissue Eng Regen Med, 5: 253-263.

Puppi D, Mota C, Gazzarri M, Dinucci D, Gloria A, Myrzabekova M, Ambrosio L, Chiellini F. 2012, Additive manufacturing of wet-spun polymeric scaffolds for bone tissue engineering, Biomed Microdevices, 14: 1115-1127.

Puppi D, Dinucci D, Bartoli C, Mota C, Migone C, Dini F, Barsotti G, Carlucci F, Chiellini F. 2011b, Development of 3D wet-spun polymeric scaffolds loaded with antimicrobial agents for bone engineering, J Bioact Compat Pol, 26: 478-492.

Quarles LD, Yohay DA, Lever LW, Caton R, Wenstrup RJ. 1992, Distinct proliferative and differentiated stages of murine MC3T3-E1 cells in culture: An in vitro model of osteoblast development, J Bone Miner Res, 7: 683-692.

Rivard C, Chaput C, Rhalmi S, Selmani A. 1996, Bio-absorbable synthetic polyesters and tissue regeneration. A study of threedimensional proliferation of ovine chondrocytes and osteoblasts, Ann Chir 50 651-658.

Salgado AJ, Coutinho OP, Reis RL. 2004, Bone Tissue Engineering: State of the Art and Future Trends, Macromol Biosci, 4: 743-765.

Sarkar SD, Farrugia BL, Dargaville TR, Dhara S. 2013, Chitosan-collagen scaffolds with nano/microfibrous architecture for skin tissue engineering, $J$ Biomed Mater Res A, 101: 3482-3492.

Shor L, Guceri S, Wen X, Gandhi M, Sun W. 2007, Fabrication of three-dimensional polycaprolactone/hydroxyapatite tissue scaffolds and osteoblast-scaffold interactions in vitro, Biomaterials, 28: 5291-5297.

Sobral JM, Caridade SG, Sousa RA, Mano JF, Reis RL. 2011, Three-dimensional plotted scaffolds with controlled pore size gradients: Effect of scaffold geometry on mechanical performance and cell seeding efficiency, Acta Biomaterialia, 7: 1009-1018.

Soper DS. 2012. Analysis of Variance (ANOVA) Calculator - One-Way ANOVA from Summary Data (Online Software). http://www.danielsoper.com/statcalc3)

St-Pierre J-P, Gauthier M, Lefebvre L-P, Tabrizian M. 2005, Three-dimensional growth of differentiating MC3T3-E1 pre-osteoblasts on porous titanium scaffolds, Biomaterials, 26: 7319-7328.

Steinbüchel A, Valentin HE. 1995, Diversity of bacterial polyhydroxyalkanoic acids, FEMS Microbiol Lett, 128: 219-228.

Sun J, Dai Z, Zhao Y, Chen GQ. 2007, In vitro effect of oligo-hydroxyalkanoates on the growth of mouse fibroblast cell line L929, Biomaterials, 28: 3896-3903. 
Tuzlakoglu K, Reis RL. 2008, 'Chitosan-based scaffolds in orthopaedic applications' in Natural-based polymers for biomedical applications, ed Reis RL, Woodhead, Cambridge; $357-373$

Tuzlakoglu K, Pashkuleva I, Rodrigues MT, Gomes ME, van Lenthe GH, Muller R, Reis RL. 2010, A new route to produce starch-based fiber mesh scaffolds by wet spinning and subsequent surface modification as a way to improve cell attachment and proliferation, J Biomed Mater Res A, 92: 369-377.

Van Bael S, Chai YC, Truscello S, Moesen M, Kerckhofs G, Van Oosterwyck H, Kruth JP, Schrooten J. 2012, The effect of pore geometry on the in vitro biological behavior of human periosteum-derived cells seeded on selective laser-melted Ti6Al4V bone scaffolds, Acta Biomaterialia, 8: 2824-2834.

Wang J, Yu X. 2010, Preparation, characterization and in vitro analysis of novel structured nanofibrous scaffolds for bone tissue engineering, Acta Biomaterialia, 6: 3004-3012.

Wang L, Wang ZH, Shen CY, You ML, Xiao JF, Chen GQ. 2010, Differentiation of human bone marrow mesenchymal stem cells grown in terpolyesters of 3hydroxyalkanoates scaffolds into nerve cells, Biomaterials, 31: 1691-1698.

Wang Y, Jiang X-L, Yang S-C, Lin X, He Y, Yan C, Wu L, Chen G-Q, Wang Z-Y, Wu Q. 2011, MicroRNAs in the regulation of interfacial behaviors of MSCs cultured on microgrooved surface pattern, Biomaterials, 32: 9207-9217.

Wang Y, Gao R, Wang P-P, Jian J, Jiang X-L, Yan C, Lin X, Wu L, Chen G-Q, Wu Q. 2012, The differential effects of aligned electrospun PHBHHx fibers on adipogenic and osteogenic potential of MSCs through the regulation of PPAR $\gamma$ signaling, Biomaterials, 33: 485-493.

Wang YW, Wu Q, Chen GQ. 2004, Attachment, proliferation and differentiation of osteoblasts on random biopolyester poly(3-hydroxybutyrate-co-3-hydroxyhexanoate) scaffolds, Biomaterials, 25: 669-675.

Wang YW, Wu Q, Chen J, Chen GQ. 2005a, Evaluation of three-dimensional scaffolds made of blends of hydroxyapatite and poly(3-hydroxybutyrate-co-3-hydroxyhexanoate) for bone reconstruction, Biomaterials, 26: 899-904.

Wang YW, Yang F, Wu Q, Cheng YC, Yu PH, Chen J, Chen GQ. 2005b, Effect of composition of poly(3-hydroxybutyrate-co-3-hydroxyhexanoate) on growth of fibroblast and osteoblast, Biomaterials, 26: 755-761.

Whited BM, Whitney JR, Hofmann MC, Xu Y, Rylander MN. 2011, Pre-osteoblast infiltration and differentiation in highly porous apatite-coated PLLA electrospun scaffolds, Biomaterials, 32: 2294-2304.

Williamson MR, Coombes AGA. 2004, Gravity spinning of polycaprolactone fibres for applications in tissue engineering, Biomaterials, 25: 459-465.

Wu L-P, You M, Wang D, Peng G, Wang Z, Chen G-Q. 2013, Fabrication of carbon nanotube (CNT)/poly(3-hydroxybutyrate-co-3-hydroxyhexanoate) (PHBHHx) nanocomposite films for human mesenchymal stem cell (hMSC) differentiation, Polymer Chemistry, 4: 4490-4498.

Wutticharoenmongkol P, Pavasant P, Supaphol P. 2007, Osteoblastic phenotype expression of MC3T3-E1 cultured on electrospun polycaprolactone fiber mats filled with hydroxyapatite nanoparticles, Biomacromolecules, 8: 2602-2610.

Yang H-X, Sun M, Zhou P. 2009, Investigation of water diffusion in poly(3hydroxybutyrate-co-3-hydroxyhexanoate) by generalized two-dimensional correlation ATR-FTIR spectroscopy, Polymer, 50: 1533-1540. 
Yang M, Zhu S, Chen Y, Chang Z, Chen G, Gong Y, Zhao N, Zhang X. 2004, Studies on bone marrow stromal cells affinity of poly (3-hydroxybutyrate-co-3hydroxyhexanoate), Biomaterials, 25: 1365-1373.

Ye C, Hu P, Ma M-X, Xiang Y, Liu R-G, Shang X-W. 2009, PHB/PHBHHx scaffolds and human adipose-derived stem cells for cartilage tissue engineering, Biomaterials, 30: 4401-4406.

Zein I, Hutmacher DW, Tan KC, Teoh SH. 2002, Fused deposition modeling of novel scaffold architectures for tissue engineering applications, Biomaterials, 23: 1169-1185.

Zhang X, Hua H, Shen X, Yang Q. 2007, In vitro degradation and biocompatibility of poly(l-lactic acid)/chitosan fiber composites, Polymer, 48: 1005-1011.

Zhao K, Deng Y, Chun Chen J, Chen GQ. 2003, Polyhydroxyalkanoate (PHA) scaffolds with good mechanical properties and biocompatibility, Biomaterials, 24: 1041-1045.

Zhao Y, Zou B, Shi Z, Wu Q, Chen GQ. 2007, The effect of 3-hydroxybutyrate on the in vitro differentiation of murine osteoblast MC3T3-E1 and in vivo bone formation in ovariectomized rats, Biomaterials, 28: 3063-3073.

\section{Ethics}

We wish to confirm that no ethics conflict can be arisen from our publication

\section{Original Publication}

The manuscript contains original unpublished work and is not being submitted for publication elsewhere at the same time.

\section{Conflict of Interest}

Authors are responsible for disclosing all financial and personal relationships between themselves and others that might bias their work.

Potential conflicts from the work reported in this manuscript do not exist. 
